\title{
The Effect of Pedestrian Traffic on the Dynamic Behavior of Footbridges
}

M. Studničková

The dynamic response of a footbridge depends namely on the natural frequencies of the structure in vertical, in horizontal and in torsion. If any of the frequencies in vertical is in the range $1.0 \mathrm{~Hz}$ to $3.0 \mathrm{~Hz}$, the dynamic response from moving people can be significant. In this case it is necessary to calculate vibrations taking into account both serviceability and ultimate limit states. The same problem arises when any of the frequencies in horizontal (transversal) or in torsion are in the range $0.5 \mathrm{~Hz}$ to $1.5 \mathrm{~Hz}$. Such frequencies haveare found namely in footbridges with larger spans or cable-stayed and suspension footbridges.

A unique cable-stayed footbridge with prestressed concrete was dynamically analyzed and the dynamic response to simulated pedestrian loading was calculated. The calculated effects were compared with the pedestrian comfort criteria for serviceability limit states. These criteria are defined in terms of maximum acceptable acceleration of the bridge deck.

Keywords: vibrations, footbridge, dynamic actions due to pedestrians, acceptance criteria, response, serviceability.

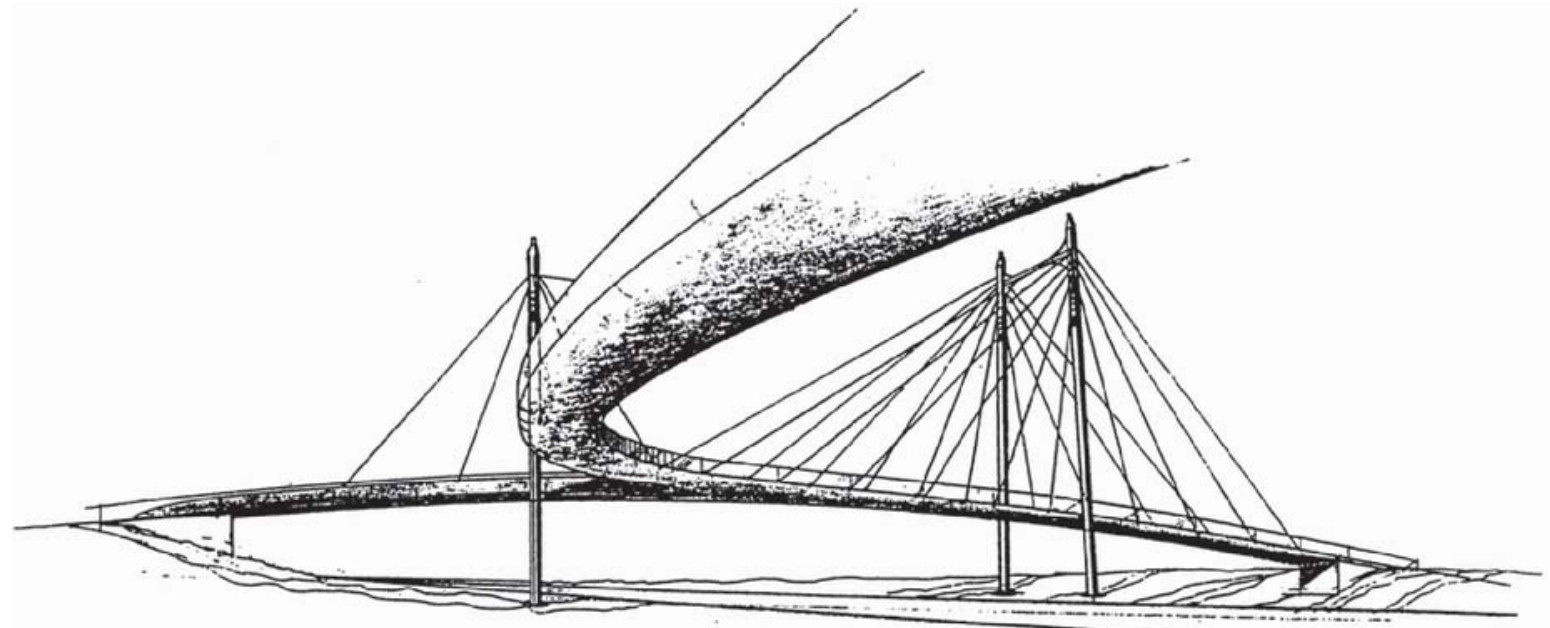

Fig. 1: Artistic view of the footbridge

\section{Introduction}

Modern footbridges are usually slender, light-weight structures, frequently of unusual structural systems, e.g. of stressed ribbon, suspended or cable-stayed types. If such footbridges are designed for static loads only they may be susceptible to vertical as well as to horizontal vibrations. Hence a dynamic design is often necessary.

Rhythmical human body motion, e.g., walking, running or jumping, can cause heavy vibrations of structures. There have been several accidents in dance halls, grandstands and footbridges caused by marching, dancing or applauding people. In recent years there have been examples of footbridges that have proved to be unacceptably lively to pedestrians. The latest case is the Millennium Bridge in London.

A cable-stayed footbridge with prestressed concrete was designed over the main road in Ústí nad Labem in North Bohemia by SÚDOP Praha [1]. The structure in plan consist of a $\mathrm{Y}$ form, and is suspended on two pylons. An artistic view of the structure is shown in Fig. 1.

The pans of the main bridge are $26.1 \mathrm{~m}+44.7 \mathrm{~m}+$ $17.1 \mathrm{~m}$, the curved pavement ramp is $24.8 \mathrm{~m}$ - see Fig. 2. The height of the I pylon is $14 \mathrm{~m}$, while the height of the $\mathrm{H}$ pylon is $17 \mathrm{~m}$.

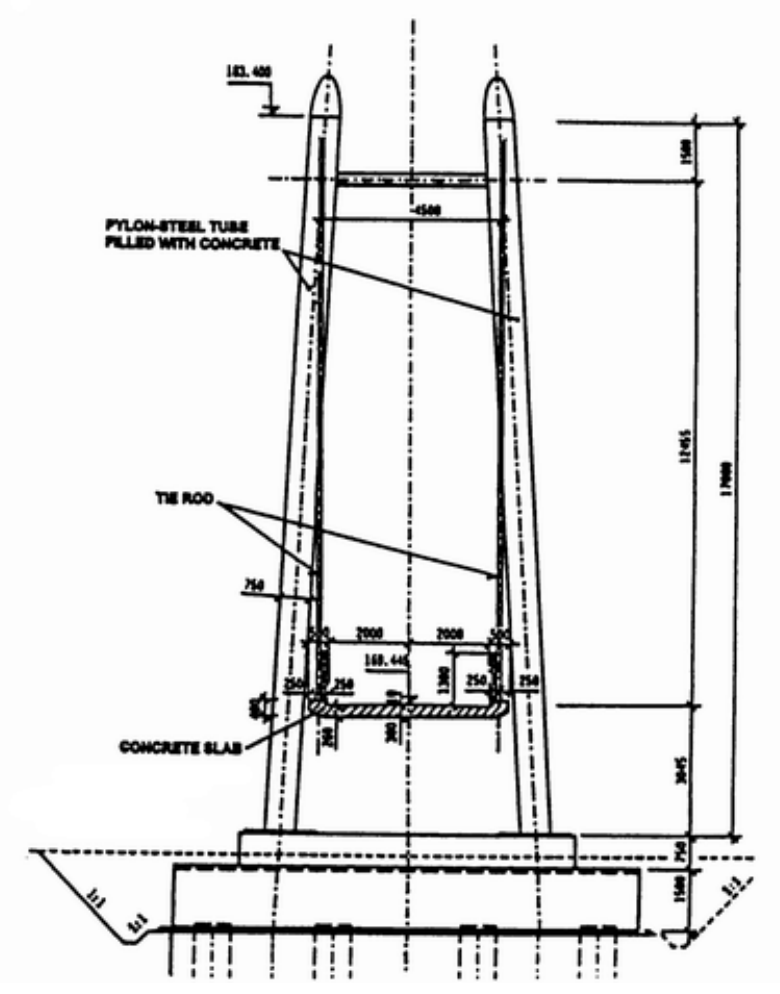

Fig. 2: Section of the footbridge 


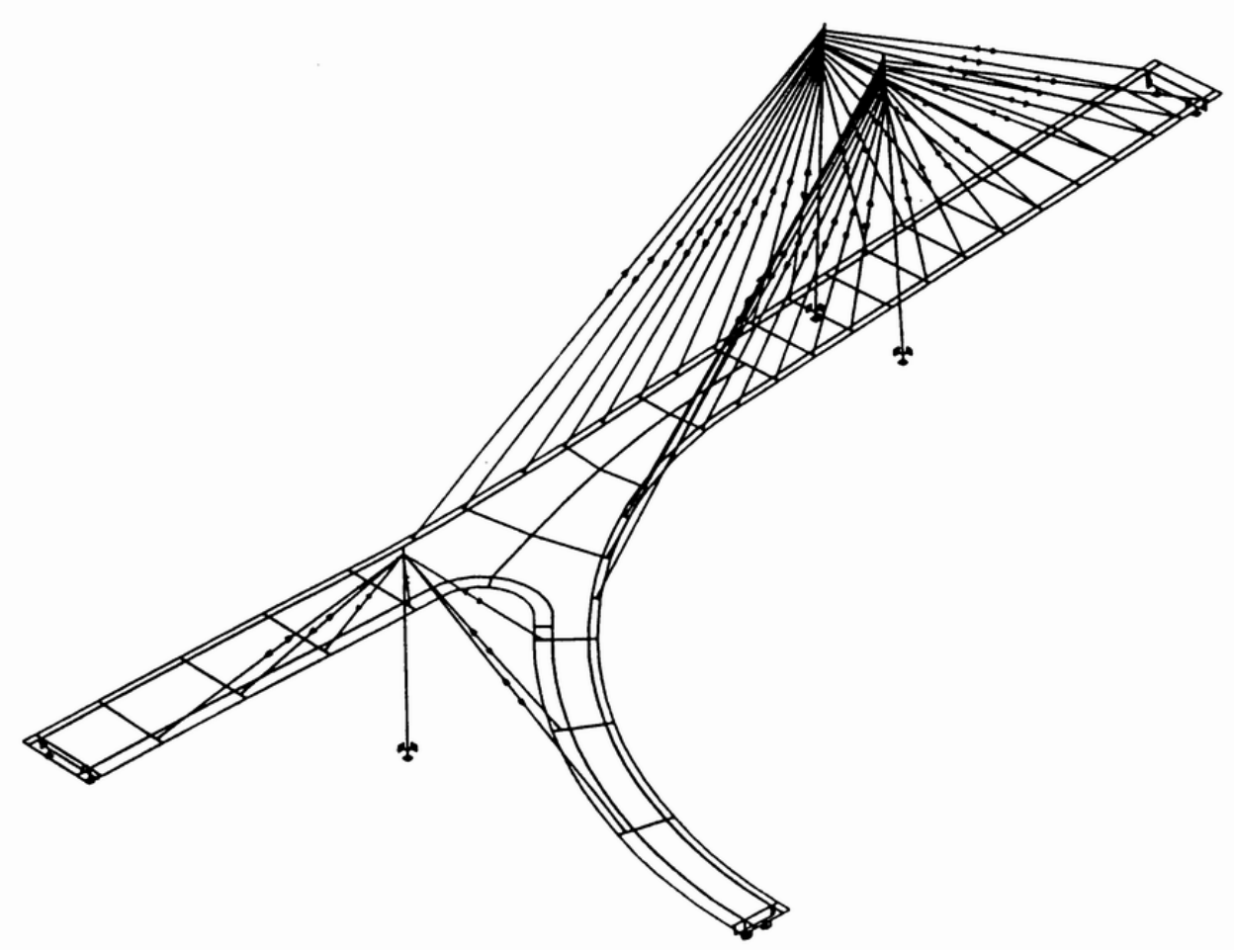

Fig. 3: Computational model of the structure

\section{Model of the structure}

The computational model of a footbridge for dynamic analysis usually consists of truss, beam and 2D elements. The correct results of the eigenvalue analysis are strongly dependent on the boundary conditions. The implementation of these into the calculation must be carefully considered.

The computational model of the bridge is shown in Fig. 3.

\section{Dynamic analysis}

The dynamic analysis consists of computational eigenvalue analysis and of the analysis of the response to the time-dependent loads caused by pedestrians.

The damping of the analysed footbridge was considered by Rayleigh's damping proportional to mass and stiffness with values of coefficients corresponding to logarithmic damping decrement $\vartheta=0.02$.

The results of the eigenvalue analysis - five lowest frequencies - are summarised in Table 1, and the corresponding mode shapes in Fig. 4-7.

\section{Acceptance criteria}

The measured or calculated vibration amplitudes of a footbridge must be compared with the acceptance criteria. The acceptance criteria are frequency-dependent and in general they are given in units of acceleration.

In the case of vertical vibrations, maximum acceleration amplitudes of $0.5 \mathrm{~ms}^{-2}$ to $1.0 \mathrm{~ms}^{-2}$, i.e. $5 \%$ to $10 \%$ of gravity $g$ may be accepted - see Fig. 8 . Some countries have given considerable attention to the specification of tolerable vibration levels on bridges and footbridges, and the ascertained criteria have been incorporated into the design standards. Fig. 9 shows the criteria of acceptability of vertical vibrations above $1 \mathrm{~Hz}$ given in the standards of the United Kingdom (BS 5400, 1978), Canada (OBDC, 1983) and international ISO Standards (ISO 2631). Experience has shown that most users tolerate even slightly higher values than those pertaining to the hatched part of Fig. 9.

People are much more sensitive to horizontal vibrations when walking or running than to vertical vibrations. Therefore, an acceptance value of $1 \%$ to $2 \%$ in horizontal is re-

Table 1: Natural frequencies of the footbridge

\begin{tabular}{|c|c|l|}
\hline Mode & Frequency $f_{i}[\mathrm{~Hz}]$ & \multicolumn{1}{c|}{ Shape identifier } \\
\hline 1 & 0.967 & superstructure horizontal longitudinal \\
\hline 2 & 1.485 & girder vertical bending \\
\hline 3 & 1.985 & girder combined vertical bending + horizontal transverse \\
\hline 4 & 2.303 & girder vertical bending + pylon H horizontal \\
\hline 5 & 2.808 & girder vertical bending + pylon H horizontal \\
\hline
\end{tabular}




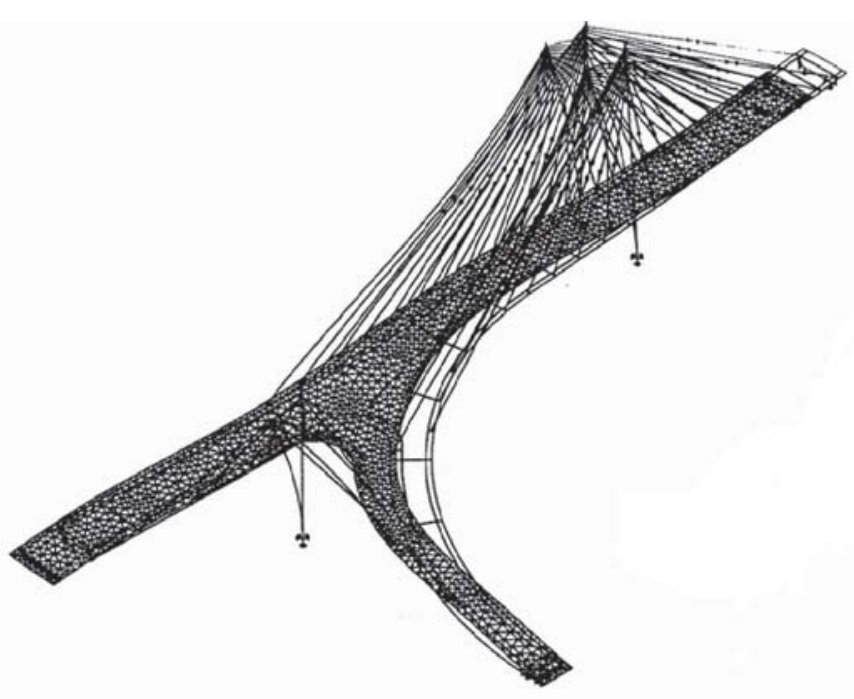

Fig. 4: $1^{\text {st }}$ mode of the bridge $f_{1}=0.967 \mathrm{~Hz}$

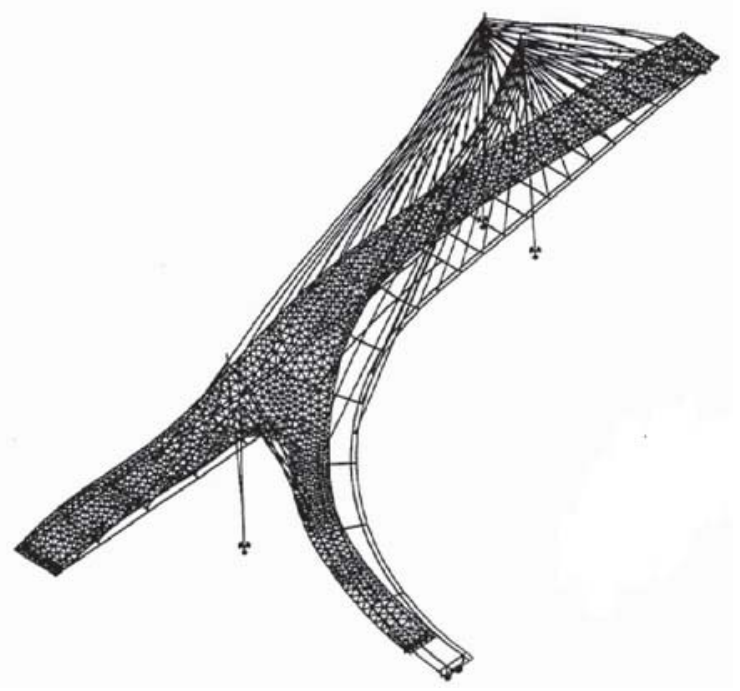

Fig. 6: $3^{\text {rd }}$ mode of the bridge $f_{3}=1.985 \mathrm{~Hz}$

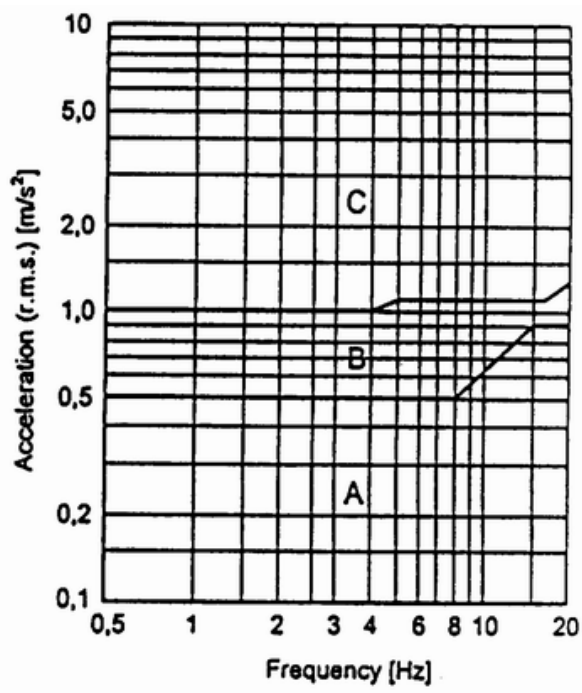

Region A: acceptable

Region B: bearable

Region C: unacceptable

Fig. 8: Criterion for vertical accelerations

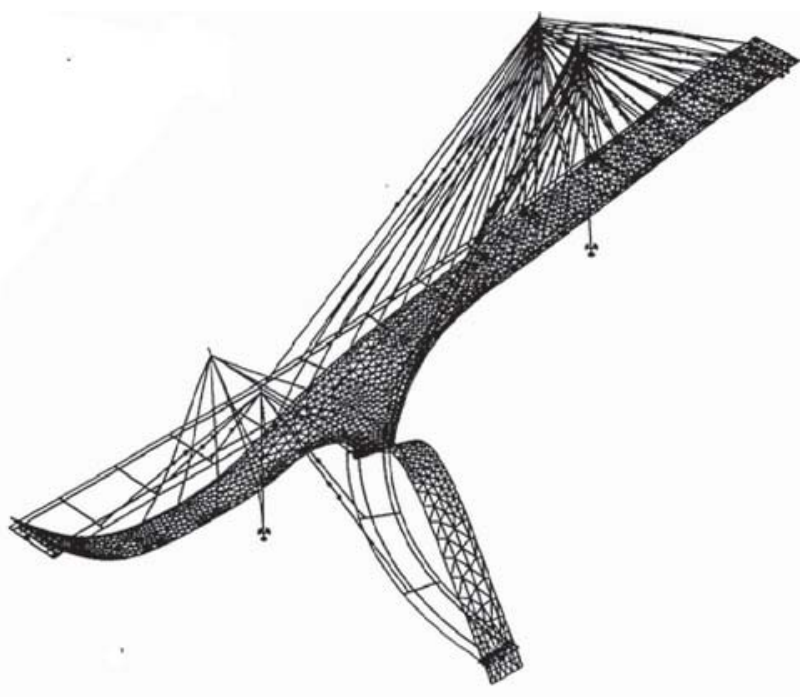

Fig. 5: $2^{\text {nd }}$ mode of the bridge $f_{2}=1.485 \mathrm{~Hz}$

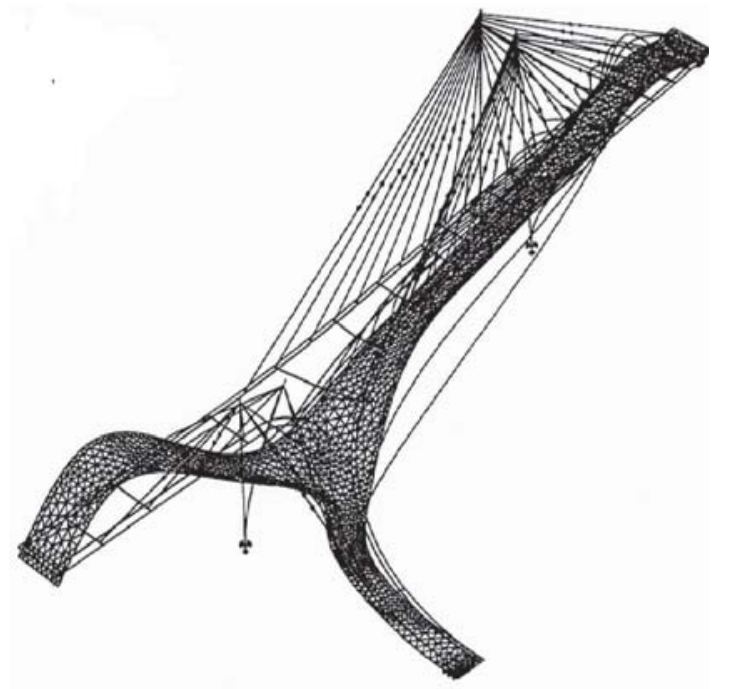

Fig. 7: $4^{\text {th }}$ mode of the bridge $f_{4}=2.303 \mathrm{~Hz}$
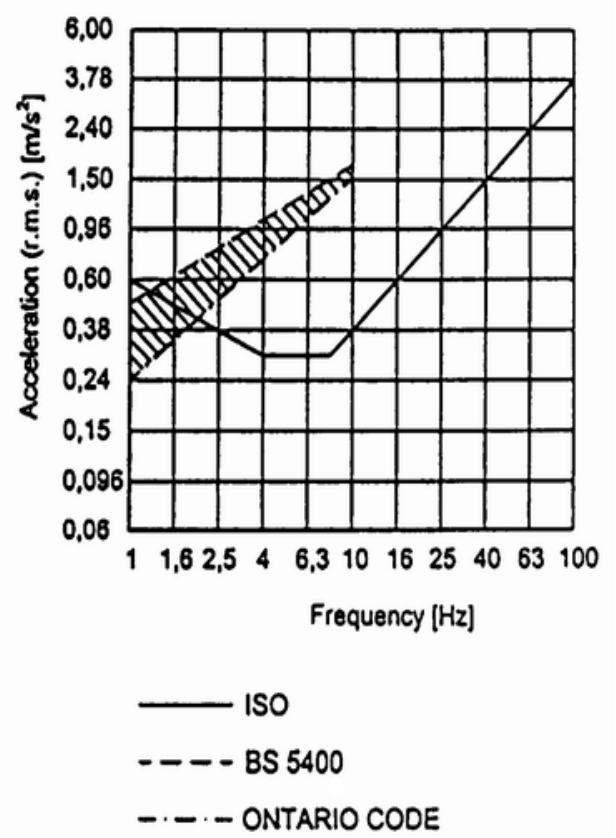

Fig. 9: Acceptable level of vertical acceleration 


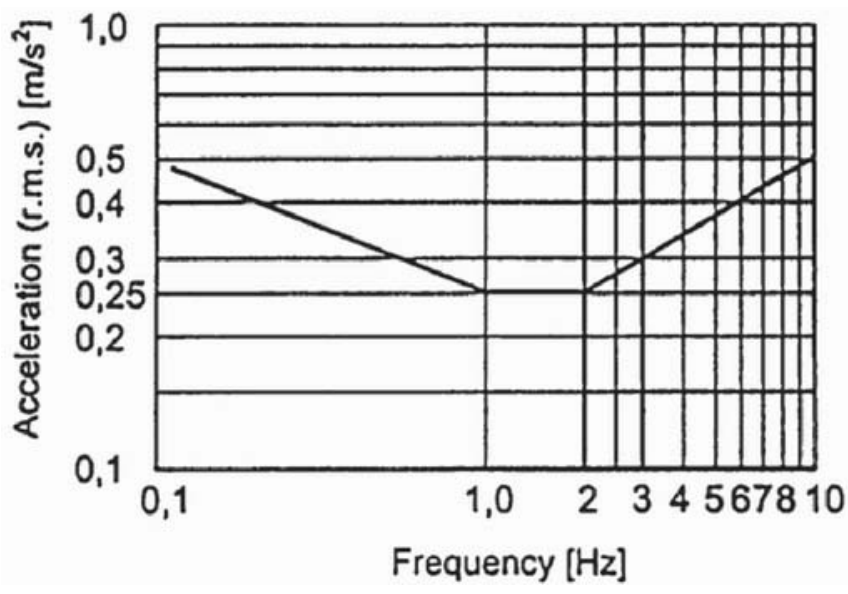

Fig. 10: Proposal of a criterion for horizontal transverse vibrations

commended. The available sources provide very little data. Nevetherless, an approximate criterion can be proposed - see Fig. 10.

\section{Dynamic forces induced by pedestrians}

Moving people excite the footbridge in vertical, in horizontal (longitudinally or transversally) and in torsion. The response of a footbridge depends namely on the pacing frequency (walking, running, jumping), the time function of the vertical and horizontal dynamic action, the number of persons involved, and the dynamic characteristics of the footbridge.

The action force $F_{\mathrm{p}}(t)$ due to a single person can be expressed with sufficient accuracy as the sum of the static force (the weight of a person) and the first three harmonic components of the excitation force [3]

$$
\begin{aligned}
F(t)= & G+G_{1} \sin 2 \pi f_{\mathrm{p}} t+G_{2} \sin \left(4 \pi f_{\mathrm{p}} t-\varphi_{2}\right)+ \\
& +G_{3} \sin \left(6 \pi f_{\mathrm{p}} t-\varphi_{3}\right)
\end{aligned}
$$

where

$G \quad$ Weight of a person (usually $G=800 \mathrm{~N}$ )

$G_{1} \quad$ Load amplitude to the first harmonic component

$G_{2} \quad$ Load amplitude to the second harmonic component

$G_{3} \quad$ Load amplitude to the third harmonic component

$f_{\mathrm{p}} \quad$ Pace frequency

$\varphi_{2} \quad$ Phase shift between the first and second harmonic components

$\varphi_{3} \quad$ Phase shift between the first and third harmonic components.

Phase shifts ji can be introduced approximately with values of $\varphi_{2}=\varphi_{3}=\pi / 2$.

For standard walking, the frequency of $2 \mathrm{~Hz}$ is most frequent. The results of a number of measurements by a number of authors are presented in [3], with the conclusion that the typical pace frequency of ordinary people is subject to Gaussian distribution with a mean value of $f_{\mathrm{p}}=2 \mathrm{~Hz}$ and the standard deviation of $\sigma_{f}=0.15 \mathrm{~Hz}$.
During running at the double, the frequency fluctuates within the limits of $2.4 \mathrm{~Hz}$ and $2.7 \mathrm{~Hz}$. During sprinting it can be as high as $5 \mathrm{~Hz}$. However, pace frequencies higher than $3.5 \mathrm{~Hz}$ on footbridges are rare.

Vandals try to tune the structure to one (most frequently the lowest) natural frequency within the limits of $0.5 \mathrm{~Hz}$ and $4.5 \mathrm{~Hz}$. Such cases do not involve merely excitation by footsteps, but also various methods of periodic force excitation with the objective of making the footbridge vibrate with the greatest possible intensity.

In practical cases the dynamic forces due to moving people can be simplified, and it is considered that only the resonant part of the dynamic action excites the bridge (e.g. [4]).

In this case the concentrated dynamic action for a group of pedestrians can be expressed in the form for vertical vibrations

$$
F_{\mathrm{pv}}(t)=280 k_{\mathrm{v}}\left(f_{\mathrm{v}}\right) \sin 2 \pi f_{\mathrm{v}} t[\mathrm{~N}]
$$

for horizontal vibrations

$$
F_{\mathrm{ph}}(t)=70 k_{\mathrm{h}}\left(f_{\mathrm{h}}\right) \sin 2 \pi f_{\mathrm{h}} t \quad[\mathrm{~N}]
$$

where

$f_{\mathrm{v}} \quad$ is a bending natural frequency of the bridge in vertical closest to $2.0 \mathrm{~Hz}$,

$f_{\mathrm{h}} \quad$ is a bending natural frequency of the bridge in horizontal closest to $1.0 \mathrm{~Hz}$,

$k_{\mathrm{v}}\left(f_{\mathrm{v}}\right), k_{\mathrm{h}}\left(f_{\mathrm{h}}\right) \quad$ are magnifying factors given in Fig. 11.

Forces (2) and (3) are applied in the location of maximum displacement of the natural mode.

For long and wide footbridges the dynamic load model of a continuous stream of pedestrians is used. This model consists of a uniformly distributed pulsating load acting in vertical or (separately) in horizontal direction. This load should be applied on the relevant areas of the footbridge deck (e.g. span by span or on the half-wavelength of the mode of vibration under consideration), for verification of the specified comfort criteria - see Fig. 8-10, as well as for an assessment of the inertia effects in order to obtain the most unfavorable effect.

The load model of a continuous stream of pedestrians can be expressed in the form:

for vertical vibrations

$$
q_{\mathrm{sv}}=12.6 k_{\mathrm{v}}\left(f_{\mathrm{v}}\right) \sin 2 \pi f_{\mathrm{v}}(t)\left[\mathrm{Nm}^{-2}\right]
$$

for horizontal vibrations

$$
q_{\mathrm{sh}}=12.6 k_{\mathrm{h}}\left(f_{\mathrm{h}}\right) \sin 2 \pi f_{\mathrm{h}}(t)\left[\mathrm{Nm}^{-2}\right]
$$

where all symbols are as already defined.

\section{Dynamic effects of pedestrian loading}

The lowest natural frequency in vertical bending is $f=1.48 \mathrm{~Hz}$ with the greatest amplitudes on the curved ramp. The frequency is lower than $1.6 \mathrm{~Hz}$ and the dynamic response to the pedestrians does not need to be checked.

The third natural frequency of the bridge $f=1.98 \mathrm{~Hz}$ belongs to the combined natural mode (vertical + horizontal) and the value of the frequency is the same as the most fre- 

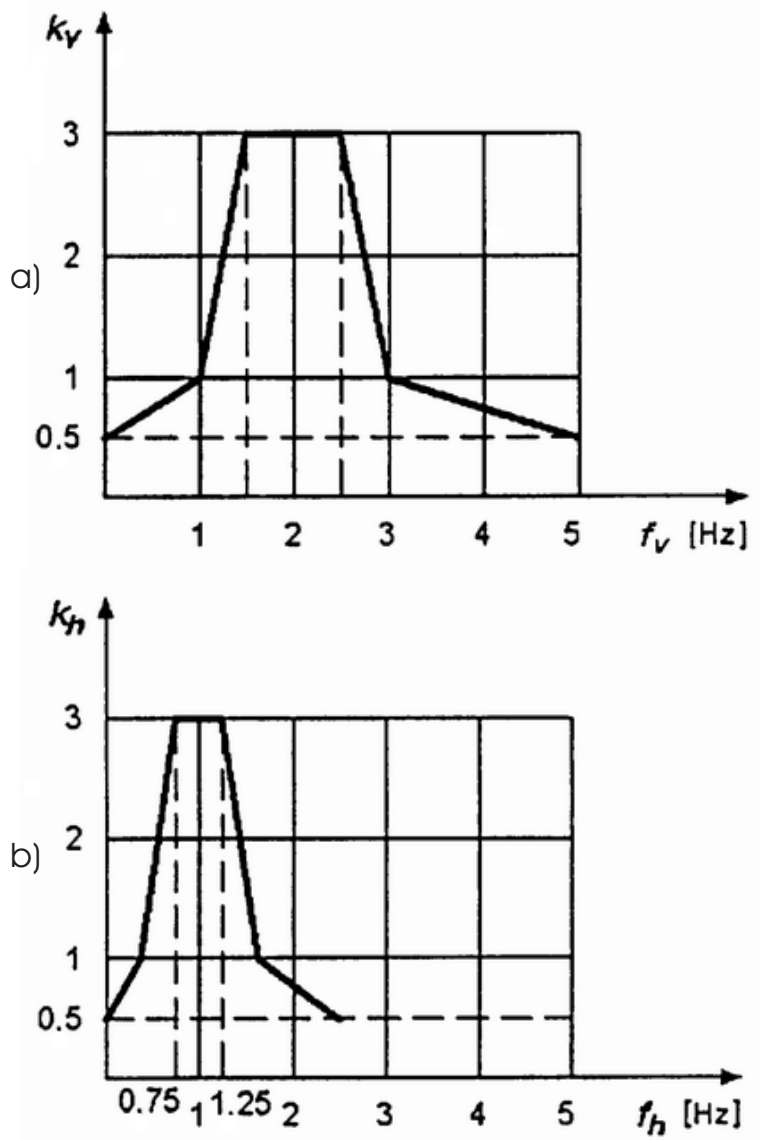

Fig. 11: Factors a) $k_{\mathrm{v}}\left(f_{\mathrm{v}}\right)$, b) $k_{\mathrm{h}}\left(f_{\mathrm{h}}\right)$

quent pace frequency $2 \mathrm{~Hz}$. The dynamic force of a group of pedestrians given by (2) was applied in the forced vibration calculation. The maximum calculated value of the acceleration response is

$$
a_{\max , \mathrm{v}}=0.01 \mathrm{~ms}^{-2} \text {. }
$$

According to Figs. 8 and 9, the limit value for acceleration is about $0.7 \mathrm{~ms}^{-2}$. The calculated value of acceleration is very small and the pedestrians do not threaten the footbridge. The footbridge is very weighty, and walking people are not able to bring it into vibration. Even the continuous stream of pedestrians modeled by (4) does not give rise to larger vibrations.

\section{Conclusion}

Modern footbridges have low damping, relatively small stiffness and are susceptible to vibrations generated by pedestrians. Footbridges with low damping (logarithmic damping decrement $\vartheta=0.03$ ) and a natural frequency in vertical bending within the limits of $1.6 \mathrm{~Hz}$ and $2.4 \mathrm{~Hz}$ or $3.3 \mathrm{~Hz}$ and $4.5 \mathrm{~Hz}$ (regions of the first and second harmonic of the pace frequency) usually react to pedestrian traffic with a significant response.

The calculation of natural vibrations (natural frequencies and modes) must be performed carefully, using approved software. Correct results of the dynamic analysis are strongly dependent on the boundary conditions. If the designer has little experience, a specialist 's advice is recommended.

The response of a footbridge to pedestrian actions should be computed in the design stage. If the computed response is higher than provided by the criteria - Figs. 8, 9, 10- it is advisable to change the structural system, to increase damping and stiffness, or to give consideration to applying of a vibration absorber. The definitive vibration absorber tuning is then based on the dynamic footbridge characteristics ascertained by measurements of the behavior of the erected structure. This paper shows that a detailed dynamic analysis in the stage of design enables the susceptibility of a footbridge to be determined. The structural system can be modified, or the material can be changed, thus ensuring that the design of the footbridge will comply with the criteria of serviceability and the ultimite limit states without additional measures.

\section{Acknowledgment}

This research has been supported by grant No 103/03/ /0082 "Nonlinear response of structures under accidental actions and pedestrian dynamic actions" of the Czech Grant Agency, and by Ministry of Education and Youth research project J04/98/210000029 "Risk engineering and reliability of technical systems".

\section{References}

[1] SÚDOP Praha: Project SO A 252 The footbridge over Žižkova street, Prague, June 2002.

[2] Studničková M.: "The assessment of footbridge vibrations according to Eurocodes" (in Czech). Stavebni obzor 4, (2001), pp. 296-299.

[3] Bachmann H., Amman W.: "Vibrations in structures induced by man and machines". IABSE Structural Engineering Document 3e, 1987.

[4] prEN 1991-2 Actions on structures - Part 2: “Traffic loads on bridges", CEN, July 2001.

Dr. Marie Studničková

Phone: +420 224353503

Fax: +420224353511

e-mail: studnic@klok.cvut.cz

Czech Technical University in Prague

Klokner Institute

Šolínova 7

16608 Prague 6, Czech Republic 